\title{
Evaluation of an intensive insulin transition protocol in the intensive care unit setting: a before and after study
}

\author{
Leigh Anne JACOBSON, Kathleen JERGUSON, LeeAnna SPIVA, Danielle FRASER.
} Received (first version): 15-Sep-2011 Accepted: 17-Jan-2012

\begin{abstract}
$^{*}$
The benefits of controlling blood glucose levels in intensive care units (ICUs) are well documented. Objective: This study determined the effectiveness and safety of a standardized transition order set for converting a continuous insulin infusion to a subcutaneous insulin regimen in non-cardiovascular surgery ICUs patient population.

Methods: A retrospective study was conducted. Patients presenting with diabetic ketoacidosis or hyperosmolar hyperglycemic syndrome were excluded. One hundred patients were included prior to and 100 patients were included after initiating the transition order set. Blood glucose control was reviewed for up to 72 hours following the transition. Results: A total of 115 patients were included in data analysis: 85 prior to and 30 after transition protocol. All patients transitioned using the protocol were transitioned to basal insulin, compared to only $40 \%$ of the prior to protocol group. Patients transitioned correctly per the transition order set, "per protocol," had $54 \%$ of blood sugars within the desired range, no increase in hypoglycemic events, and on average 5.56 hyperglycemic events (blood glucose $>180 \mathrm{mg} / \mathrm{dL}$ ) per person during the 72 hours compared to 6.68 and 9.00 for the prior to protocol group and the "off protocol" group (transitioned different than the protocol recommended), respectively $(p=0.05)$. There were significant differences in blood sugar control at 48 and 72 hours between the "per protocol" and "off protocol" groups $(p=0.01)$ and a $40 \%$ reduction in sliding scale or correctional insulin coverage. Conclusion: The addition of basal insulin to transition regimens resulted in fewer hyperglycemic events with no increase in hypoglycemic events. Patients transitioned "per protocol" had better glucose control demonstrated by: less hyperglycemic events, lower mean blood glucose levels at 48 and 72 hours, and lower need for correctional insulin. These findings showed benefits of glycemic control in the ICU by following a standardized transition protocol.
\end{abstract}

\footnotetext{
"Leigh Anne JACOBSON. Pharm.D. Clinical Pharmacist. WellStar Kennestone Hospital. Marietta, GA (United States).

Kathleen JERGUSON. Pharm.D. Clinical Pharmacist. WellStar Kennestone Hospital. Marietta, GA (United States).

LeeAnna SPIVA. PhD, RN, PLNC. Director of Nursing Research and Professional Practice WellStar Health System. Marietta, GA (United States).

Danielle FRASER. MS, RN, GCNS-BC, Clinical Nurse Specialist. WellStar Kennestone Hospital. Marietta, GA (United States).
}

Keywords: Insulin. Blood Glucose. Intensive Care Units. Postoperative Care. United States.

\section{EVALUACIÓN DE UN PROTOCOLO DE TRANSICIÓN DE INSULINA INTENSIVA EN UNA UNIDAD DE CUIDADOS INTENSIVOS: ESTUDIO ANTES-DESPUÉS}

\section{RESUMEN}

Los beneficios de controlar la glucemia en las unidades de cuidados intensivos (UCI) están ben documentados.

Objetivo: Este estudio determinó la efectividad y seguridad de un orden de transición estandarizado para convertir un régimen de insulina de infusión continua a un régimen de insulina subcutánea en una población de pacientes de UCI de cirugía no vascular.

Métodos: Se realizó un estudio retrospectivo. Se excluyó a los pacientes que presentaban cetoacidosis diabética o síndrome hiperglucémico hiperosmolar. Se incluyo a 100 pacientes antes y después de iniciar el sistema de transición. Se revisó la glucemia hasta 72 horas después de la transición.

Resultados: Un total de 115 pacientes fueron incluidos para el análisis de datos: 85 antes y 35 después del protocolo de transición. Todos los pacientes que transitaron usando el protocolo pasaron a insulina basal, comparados con sólo el $40 \%$ del grupo de antes del protocolo. El 54\% de los pacientes que transitaron correctamente con el protocolol, "por protocolo" tuvieron la glucemia en el rango deseado, sin aumento de eventos hipoglucémicos, y con un 5,56\% de eventos hiperglucémicos (glucemia> $180 \mathrm{mg} / \mathrm{dL}$ ) durante las 72 horas de vigilancia, comparados con el $6,68 \%$ y $9,00 \%$ respectivamente para el grupo anterior al protocolo y el grupo "fuera de protocolo" (que transitó diferente a lo recomendado por el protocolo) $(\mathrm{p}=0,05)$. Hubo diferencia significativas en el control glucémico a las 48 y 72 horas entre los grupos "por protocolo" y "fuera de protocolo" $(p=0,01)$ y un $40 \%$ de reducción en la escala descendente o cobertura de insulina de corrección. Conclusión: La adición de insulina basal a los regímenes de transición provocó menores eventos hiperglicémicos sin aumento de eventos hipoglicémicos. Los pacientes que transitaron "por protocolo" tuvieron mejor control glucémico, demostrado por: menores eventos hiperglucémicos, menores niveles medios de glucemia a las 48 y 72 horas, y menor necesidad de corrección de insulina. 
Estos hallazgos demostraron los beneficios de un control glucémico en la UCI siguiendo un protocolo estandarizado de transición.

Palabras clave: Insulina. Glucemia. Unidades de Cuidados Intensivos. Cuidados Postoperatorios. Estados Unidos.

\section{INTRODUCTION}

Hyperglycemia commonly occurs during hospitalization and is of particular concern in intensive care units (ICUs). ${ }^{1-8}$ Hyperglycemia can result from administration of medications such as glucocorticoids, parenteral feeding, or as a natural response to critical illness with increased release of stress hormones. Poor glycemic control increases the risk of infection, electrolyte abnormalities, and mortality. ${ }^{1-8}$ The importance of maintaining normoglycemia in the ICU setting has been emphasized over the past decade. ${ }^{1-8,10-15}$ Current literature supports maintaining blood glucose levels less than or equal to $180 \mathrm{mg} / \mathrm{dL}$ to adequately control blood sugar without increasing the risk of hypoglycemia. 8,19 An insulin infusion provides reliable blood glucose control and is the preferred route of administration in the ICU setting. ${ }^{19}$

At the study site, a continuous insulin infusion is recommended for ICU patients with two consecutive blood glucose readings exceeding $180 \mathrm{mg} / \mathrm{dL}$. In 2009 the study site began using Glucommander ${ }^{T M}$ devices, a computer-based algorithm that calculates insulin infusion rate adjustments based on patient specific blood glucose levels drawn by a nurse every one to two hours. ${ }^{18}$ Blood glucose levels are entered into the device, and the Glucommander ${ }^{T M}$ provides instructions on how to adjust the rate of the continuous insulin infusion. Although a physician order is required to initiate the protocol, all subsequent adjustments are nurse-driven.

The Glucommander ${ }^{\mathrm{TM}}$ machines provide safe and effective control of blood glucose levels; however, use of a continuous insulin infusion to treat hyperglycemia is restricted to the ICUs. Patients must be transitioned off the insulin infusion prior to transfer to a medical-surgical unit. Current literature favors the inclusion of scheduled subcutaneous insulin with basal, nutritional, and correction components to provide pro-active blood glucose control rather than reactive, sliding scale insulin. ${ }^{7,16,19}$ However, there is still limited evidence as to how to best transition patients safely to a subcutaneous regimen. ${ }^{20}$ At the study site, patients were transitioned off the Glucommander ${ }^{\text {TM }}$ per the discretion of the rounding physician. The transition regimens were inconsistent and at times unsuccessful, resulting in re-initiation of the insulin infusion.

In 2010, a formal transition order-set was developed by the Diabetes Task Force Committee for use in non-cardiovascular surgery ICUs to aid in transitioning patients to a subcutaneous insulin regimen. This transition order set sought to standardize how patients are transitioned and aid physicians in selecting an insulin regimen. Based on their nutritional intake, a patient was transitioned onto one of two regimens. If requiring parenteral nutrition or continuous tube feeds, the patient transitioned to a twice daily injection of a long-acting insulin and correctional insulin. If tolerating an oral diet, the patient transitioned to a once daily injection of a long-acting insulin, scheduled prandial insulin, and correctional insulin. The amount of insulin was selected based on the insulin sensitivity factor calculated by the Glucommander ${ }^{\mathrm{TM}}$. Further investigation was warranted to evaluate the safety and efficacy of the new standardized transition order set with respect to blood glucose control after discontinuing the insulin infusion.

The study's primary purpose was to determine the effectiveness of the new protocol with regards to blood glucose control up to 72 hours after discontinuation of the continuous insulin infusion (goal blood glucose $<180 \mathrm{mg} / \mathrm{dL}$ ). Secondary objectives included examining the frequency of hypoglycemic and hyperglycemic events in the sample. Hypoglycemia, per hospital protocol, was defined as blood glucose less than $70 \mathrm{mg} / \mathrm{dL}$. Hyperglycemia was defined as blood glucose greater than $180 \mathrm{mg} / \mathrm{dL}$. Patients transitioned using the new protocol had additional secondary objectives that included: the number of patients correctly transitioned per protocol and the amount of correctional insulin coverage needed.

\section{METHODS}

A retrospective study was conducted in a 633 bed, community hospital located in Georgia. The setting included four non-cardiovascular surgery ICUs. With approximately 76 ICU beds, the patients reviewed included both medical and surgical ICU.

Inclusion criteria consisted of the following: patients on the Glucommander ${ }^{\mathrm{TM}}$ more than 24 hours, patients with a stable insulin sensitivity factor for more than four hours, and patients transitioning off of the continuous insulin infusion. Exclusion criteria included: patients treated for diabetic ketoacidosis, hyperglycemic hyperosmolar syndrome, or patients not transitioned using the transition order-set.

Ethics approval was obtained from the Institutional Review Board for the Protection of Human Subjects. Patients were identified via a secure, online database. One hundred patients requiring a continuous insulin infusion during hospitalization from September 2009 to December 2009 served as the prior to protocol group. The time frame was chosen based on the most current practices.

Following full implementation of the formal transition order-set another 100 patients requiring a continuous insulin infusion during his or her hospitalization from October 2010 to March 2011 were included. If the formal transition order-set was used, the patient was included. Patients transitioned using the formal transition order-set were further separated into those patients transitioned as the protocol recommended, referred to as "per protocol," and those transitioned different than the protocol recommended, referred to as "off protocol." 


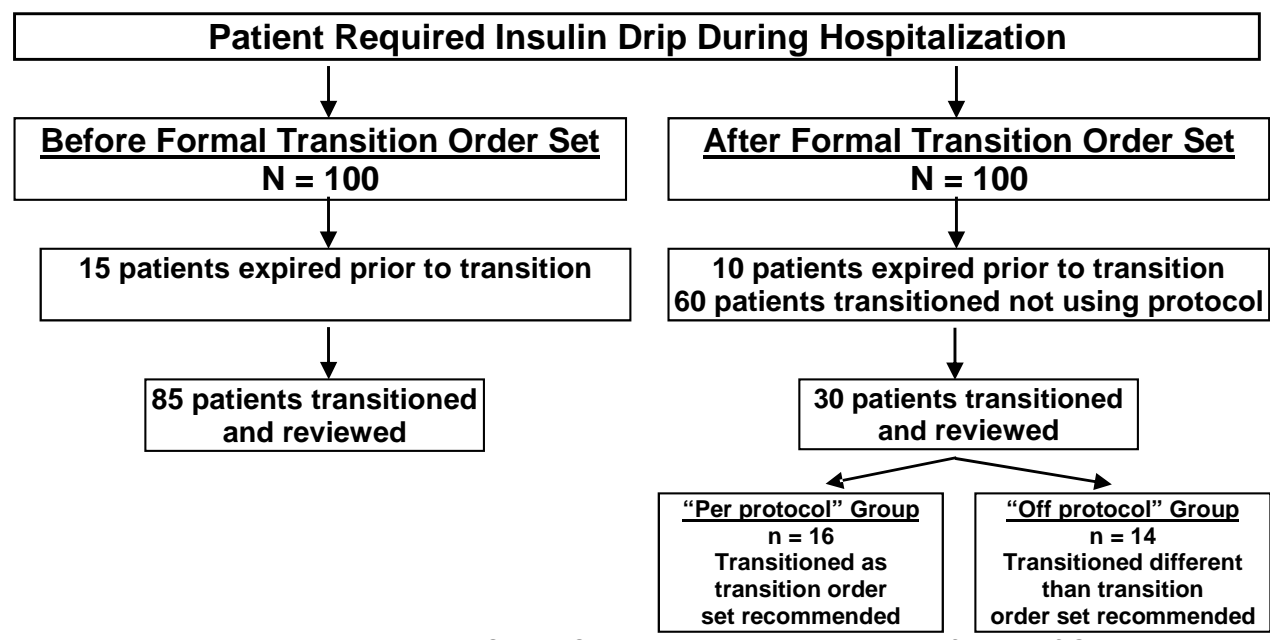

Figure 1. Patients Included in Study: Screening, Exclusions, and Definition of Groups

Baseline demographic data were collected in addition to, information on comorbidities, transition regimen, concurrent steroid therapy, nutrition, and blood glucose values for 72 hours after transitioning. Data were collected using a standardized data collection form.

Data were analyzed with descriptive and inferential statistics using SPSS for Windows Release 18.0. Statistical methods included frequencies, percentages, means, standard deviations, KruskalWallis test, and Mann-Whitney $U$ test. A p value of 0.05 was considered statistically significant.

\section{RESULTS}

A retrospective chart review was conducted on 200 patients, of which 115 patients were eligible for inclusion. Eighty-five charts were included and reviewed before the formal transition order set was implemented and 30 charts were included and reviewed after the formal transition order set was implemented. The reasons for exclusion included patient expired prior to transitioning or the transition protocol was not used for the after protocol groups (Figure 1)

For the entire sample $(\mathrm{N}=115)$, there was an equal representation of females $(56.5 \%)$ and males $(43.5 \%)$. Patients ranged in age from 25 to 86 years with a mean age of 61.57 years $(S D=12.73)$. The majority of patients had Type 2 diabetes $(65.2 \%)$, only four patients had Type 1 diabetes (3.5\%), and 36 patients did not have a pre-existing diagnosis of diabetes (31.3\%). Mean Hemoglobin A1C $(\mathrm{HgbA} 1 \mathrm{C})$ was $8.11 \quad(\mathrm{SD}=2.54)$. Fifty patients $(43.5 \%)$ were on concurrent steroid medications and the remaining $65(56.5 \%)$ were not on steroids (Table 1). The most common comorbidities consisted of the following: hypertension $n=80$ $(50.3 \%)$, coronary artery disease $n=32(20.1 \%)$, hyperlipidemia $n=31(19.5 \%)$, and cerebral vascular accident $n=8(5 \%)$ (Table 1).

Because of unequal variances, a Kruskal-Wallis nonparametric analysis of variance (ANOVA) was used to compare the prior to protocol, "per protocol," and "off protocol" treatment groups. Significant

\begin{tabular}{|c|c|c|c|c|}
\hline & $\begin{array}{c}\text { All } \\
(\mathrm{N}=115)\end{array}$ & $\begin{array}{l}\text { Prior to Protocol } \\
\quad(\mathrm{N}=85)\end{array}$ & $\begin{array}{l}\text { "Per Protocol" } \\
\quad(N=16)\end{array}$ & $\begin{array}{l}\text { "Off Protocol" } \\
(\mathrm{N}=14)\end{array}$ \\
\hline Average age in years (range) & $\begin{array}{c}61.6(25-86) \\
p=0.08\end{array}$ & $60.2(25-86)$ & $67.9(54-80)$ & $62.4(48-80)$ \\
\hline Sex (male:female) & $\begin{array}{c}50: 65 \\
p=0.16\end{array}$ & $33: 52$ & $9: 7$ & $8: 6$ \\
\hline Weight in kg (range) & $\begin{array}{l}91.6(40.9-193.0) \\
p=0.95\end{array}$ & $91.3(40.9-193.0)$ & $93.7(57.0-137.0)$ & $91.0(68.3-125.0)$ \\
\hline Avg. BMI (range) & $\begin{array}{c}32.2(17.0-66.6) \\
p=0.66\end{array}$ & $32.6(17.0-66.6)$ & $31.9(19.3-49.2)$ & $30.2(19.3-43.8)$ \\
\hline History of Diabetes & 75 & 56 & 12 & 11 \\
\hline Non-insulin Treated & 32 & 21 & 5 & 6 \\
\hline Insulin Treated & 47 & 35 & 7 & 5 \\
\hline Avg. HgbA1c (range) & $\begin{array}{c}8.1(4.9-15.7) \\
p=0.14\end{array}$ & $8.1(4.9-15.0)$ & $7.3(5.2-13.3)$ & $9.3(5.1-15.7)$ \\
\hline $\begin{array}{l}\text { Total Days on Continuous Insulin Infusion } \\
\text { (range) }\end{array}$ & $\begin{array}{c}3.2(1-17) \\
p=0.76\end{array}$ & $3.3(1-17)$ & $2.9(1-9)$ & $2.8(1-9)$ \\
\hline Concurrent Use of Steroids & $\begin{array}{c}50 \\
p=0.16\end{array}$ & 36 & 8 & 6 \\
\hline $\begin{array}{l}\text { Insulin Sensitivity Factor on Transition } \\
\text { (range) }\end{array}$ & $\begin{array}{c}0.075(0.001-0.949) \\
\mathrm{p}=0.36\end{array}$ & $0.085(0.003-0.950)$ & $0.042(0.001-0.119)$ & $0.055(0.013-0.186)$ \\
\hline $\begin{array}{l}\text { BBG Discontinuation of Insulin Infusion in } \\
\mathrm{mg} / \mathrm{dL} \text { (range) }\end{array}$ & $\begin{array}{c}121.3(61-249) \\
p=0.29\end{array}$ & $118.7(61-249)$ & $128.8(86-216)$ & $128.7(79-202)$ \\
\hline Initial Units of Basal Insulin Given (range) & $\begin{array}{c}14.4(0-120) \\
p=0.00\end{array}$ & $8.2(0-60)$ & $33.2(6-120)$ & $29.8(5-80)$ \\
\hline
\end{tabular}




\begin{tabular}{|c|c|c|c|c|}
\hline & Prior to Protocol & "Per Protocol" & "Off Protocol" & p-value \\
\hline No. of patients & 85 & 16 & 14 & \\
\hline No. of BBGs & 1155 & 199 & 194 & \\
\hline \% Transitioned with basal insulin & $40 \%$ & $100 \%$ & $100 \%$ & \\
\hline $\begin{array}{l}\text { \% of hypoglycemic BBGs } \\
(<70 \mathrm{mg} / \mathrm{dL})\end{array}$ & $1 \%$ & $2 \%$ & $4 \%$ & \\
\hline $\begin{array}{l}\text { \% of in target range BBGs } \\
(70-180 \mathrm{mg} / \mathrm{dL})\end{array}$ & $51 \%$ & $54 \%$ & $30 \%$ & \\
\hline $\begin{array}{l}\% \text { of hyperglycemic BBGs } \\
\text { (>180 mg/dL) }\end{array}$ & $48 \%$ & $44 \%$ & $66 \%$ & \\
\hline Avg. \# of hyperglycemic events per person & 6.68 & 5.56 & 9 & $p=0.01$ \\
\hline Mean BBG 24 hours (mg/dL) & 188.53 & 218.69 & 214.03 & \\
\hline Mean BBG 48 hours (mg/dL) & 189.16 & 183.02 & 227.75 & $p=0.04$ \\
\hline Mean BBG 72 hours (mg/dL) & 183.86 & 152.02 & 213.51 & $p=0.01$ \\
\hline $\begin{array}{l}\text { Avg. amount of supplemental insulin given } \\
\text { per person }\end{array}$ & 13.0 units & 10.2 units & 16.8 units & $p=0.04$ \\
\hline $\begin{array}{l}\text { Avg. amount of time before regimen } \\
\text { changed if needed }\end{array}$ & $\mathrm{n} / \mathrm{a}$ & $33 \mathrm{hrs}$ & $45 \mathrm{hrs}$ & \\
\hline
\end{tabular}

differences were found for all three groups for day two mean blood glucose levels chisquare $(3, N=100)=6.13, p=0.05$. Using the Holm's sequential Bonferroni approach, follow-up tests were conducted to evaluate pair wise differences among the groups controlling for Type I error. The results indicated a significant difference between the prior to protocol group and "off protocol" group versus the "per protocol" group. The second day mean blood glucose levels were higher in the prior to protocol group $(M=189.16 \mathrm{mg} / \mathrm{dL}, \mathrm{SD}=53.56)$ and "off protocol" group $(\mathrm{M}=227.75 \mathrm{mg} / \mathrm{dL}, \mathrm{SD}=61.22)$ than the "per protocol" group (mean $=183.02 \mathrm{mg} / \mathrm{dL}$, $\mathrm{SD}=54.89$ ). Important to note, the mean blood glucose level for day three was also lower for the "per protocol" group (M=152.02 $\mathrm{mg} / \mathrm{dL}, \mathrm{SD}=46.39)$ compared to the prior to protocol group $(\mathrm{M}=183.86$ $\mathrm{mg} / \mathrm{dL}, \quad \mathrm{SD}=55.83$ ) and "off protocol" group $(\mathrm{M}=213.51 \mathrm{mg} / \mathrm{dL}, \mathrm{SD}=75.14)$. The total amount of correctional insulin for the 72 hours was lower for the "per protocol" group ( $M=10.2$ units, $S D=8.96)$ compared to the prior to protocol group ( $M=13.0$ units, $S D=10.77$ ) and the "off protocol" group $(M=16.8$ units, $S D=8.92)$. There was no significant increase in the rate of hypoglycemic events between the groups with $1 \%, 2 \%$, and $4 \%$ of blood glucose levels considered hypoglycemic for prior to protocol, "per protocol," and "off protocol" groups, respectively $(p=0.225)$. Of interest, compared to the other groups the "per protocol" group had no severe hypoglycemic events $(B B G<50 \mathrm{mg} / \mathrm{dL})$. (Table 2 and Figure 2).

In order to examine the optimal use of the transition order set a Mann-Whitney $U$ test was conducted to evaluate the formal transition order set comparing the "per protocol" and "off protocol" groups. Significant differences were found between the two groups for the following variables: total number of hyperglycemic events within the 72 hour timeframe, mean blood glucose levels at 48 and 72 hours post transition, and the total amount of correctional insulin within the 72 hour timeframe. The "per protocol" group had a significantly lower number of hyperglycemic events within the 72 hour timeframe $(M=5.56, S D=5.19), z=52.50, p=0.01$, than the "off protocol" group (M=9, $S D=3.21)$ (Figure 3). Between 24 and 48 hours after transitioning the "per

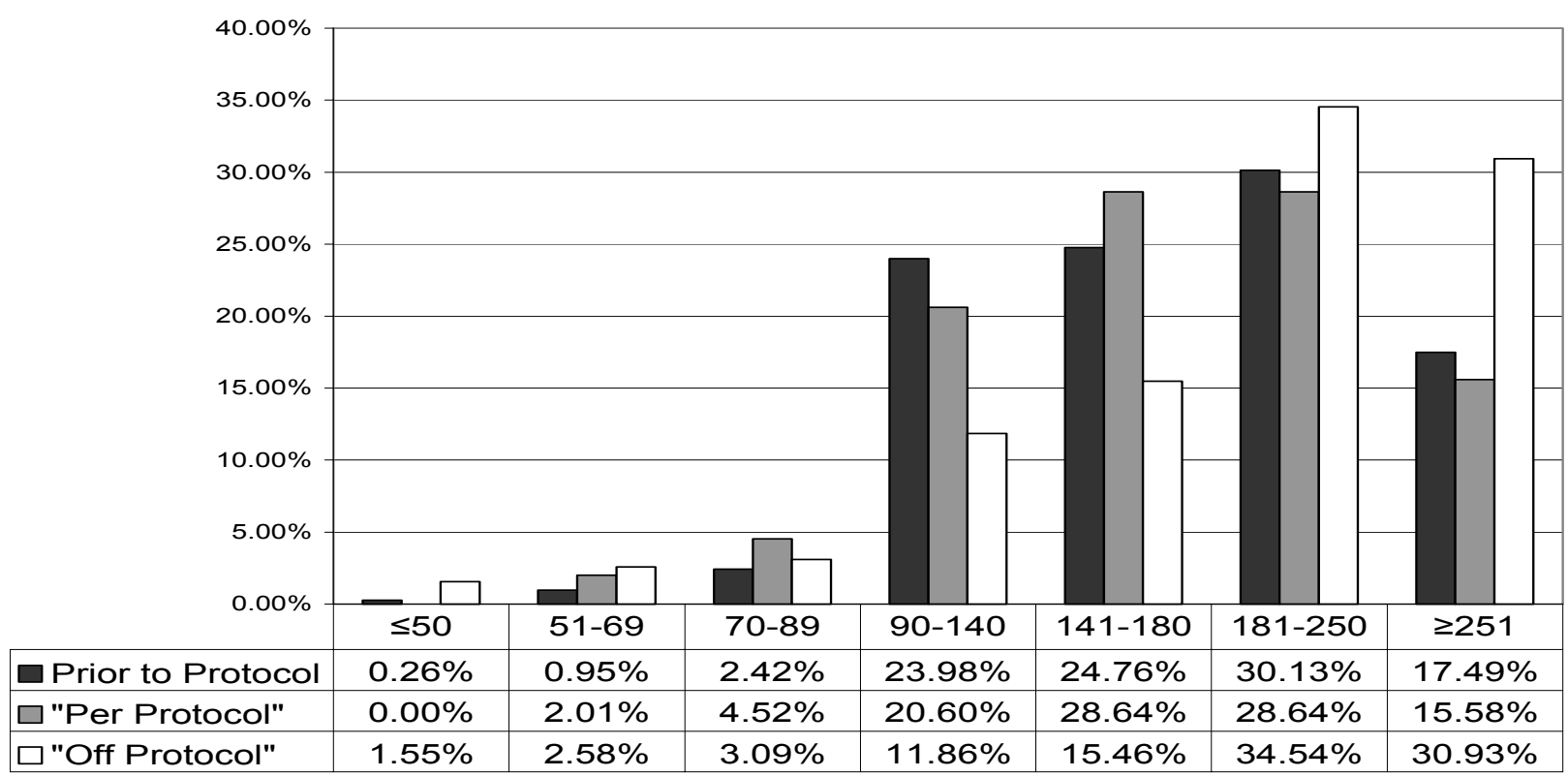

Figure 2. Blood Glucose Control Comparison: Distribution of blood glucoses within 72 hours of transitioning by range in $\mathrm{mg} / \mathrm{dL}$ 
protocol" group had significantly lower mean glucose levels $(M=183.02 \mathrm{mg} / \mathrm{dL}, \mathrm{SD}=54.89), \mathrm{z}=58$, $\mathrm{p}=0.04$, than the "off protocol" group $(\mathrm{M}=227.75$ $\mathrm{mg} / \mathrm{dL}, \mathrm{SD}=61.22$ ) (Figure 4). Between 48 and 72 hours after transitioning the "per protocol" group had significantly lower mean glucose levels $(M=152.02$ $\mathrm{mg} / \mathrm{dL}, \quad \mathrm{SD}=46.40), \quad \mathrm{z}=48.50, \quad \mathrm{p}=0.01$, than "off protocol" group $(\mathrm{M}=213.51 \mathrm{mg} / \mathrm{dL}, \quad S D=75.14)$ (Figure 4). The "per protocol" group had significantly less requirement of correctional insulin within the 72 hours from the sliding scale coverage $(M=10.2$ units, $S D=8.96), z=62.50, p=0.04$, than the "off protocol" group ( $\mathrm{M}=16.8$ units, $\mathrm{SD}=8.92)$ (Figure 5). Hypoglycemia occurred in only $2 \%$ of the "per protocol" group compared to $4 \%$ of the "off protocol" group. (Table 2 and Figure 2).

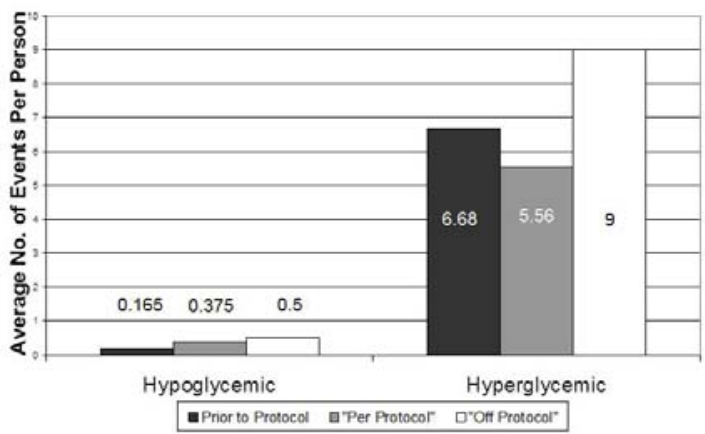

Figure 3. Blood Glucose Control Comparison: number of hypoglycemic and hyperglycemic events.

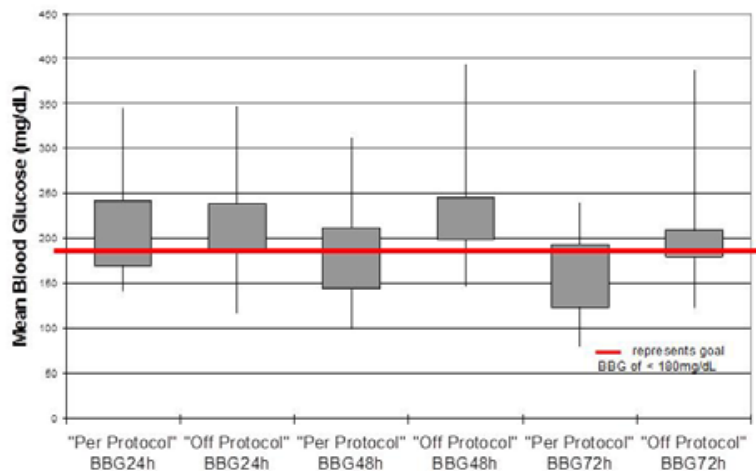

Figure 4. "Per Protocol" versus "Off Protocol:" distribution of means blood glucoses by time within 72 hours of transitioning.

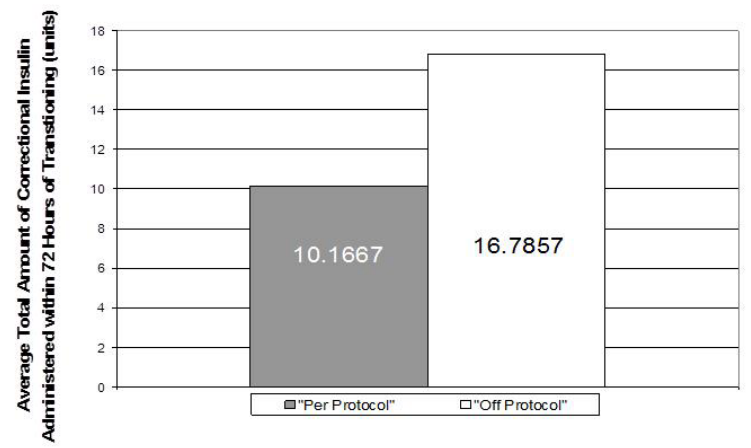

Figure 5. "Per Protocol" versus "Off Protocol:" amount of correctional insulin administered from sliding scale within 72 hours of transitioning

\section{DISCUSSION}

Current medical practice recommends combined basal-prandial insulin as a therapeutic option for the management of hyperglycemia. In this study, insulin glargine was the long acting insulin subcutaneously administered to provide blood glucose control overnight and in between meals. The prandial component, insulin lispro, includes a shorter acting subcutaneous insulin administered prior to meals. This method best simulates normal pancreatic insulin secretion. ${ }^{17}$

Critically ill patients are predisposed to hyperglycemia and have been proven to benefit from basal-prandial insulin regimens. Over the last decade, specific blood sugar goals for this patient population have varied. The NICE-SUGAR Investigators raised the blood glucose threshold to maintain blood sugar control via insulin infusions between 110 and $180 \mathrm{mg} / \mathrm{dL}$ to optimize outcomes and minimize hypoglycemia. ${ }^{8}$ While on the continuous insulin infusion and during transition, target blood glucoses were consistent with current recommendations. Regimens were encouraged to be adjusted to address blood glucoses outside of target range at any point, both hypoglycemia and hyperglycemia. This continues to be an area for improvement as regimens on average were not changed until 33 or 45 hours, "per" and "off" protocol respectively. The protocol regimen is meant for initial transitioning and is intended to be adjusted based on blood glucose levels. Insulin regimens should be increased to address continued uncontrolled blood glucose levels or decreased to accommodate return to normal insulin response as clinical status improves. Additional observation of clinical practice is needed to assess response to normalized blood sugars and prevention of hypoglycemia.

This study showed that following a standardized intensive insulin transition protocol significantly improved glycemic control. All patients transitioned using the protocol were transitioned to basal insulin providing a more proactive approach to blood sugar control. Despite the inherent increased risk of hypoglycemia using basal insulin, there was no significant increase in the number of hypoglycemic events in patients transitioned correctly per the transition protocol. In comparison to the control group prior to the transition protocol, patients transitioned "per protocol" required less correctional insulin administration and had fewer hyperglycemic events.

Additionally, patients transitioned "per protocol" had significantly better blood sugar control than patients transitioned "off protocol." All groups had poor blood sugar control during the first 24 hours but at 48 hours the "per protocol" group had significantly better blood glucose control. Blood glucose control improved further at 72 hours. The "per protocol" group also required less correctional insulin via sliding scale insulin and had fewer hyperglycemic events.

While the continuous insulin infusion provides ideal blood sugar control, it is not practical to have in non- 
ICU settings secondary to the high risk and acuity of the drug. Similar to the recommendations of The Northwestern Experience by DeSantis, the formal transition order-set was developed with the intention to better standardize the approach to discontinuing a continuous insulin infusion. ${ }^{6}$ It removes the guesswork from selecting a transition regimen in patients without a history of diabetes or patients with diabetes requiring increased coverage of elevated blood sugars.

Unlike DeSantis's protocol patients in which patients were transitioned off of the continuous insulin infusion once tolerating an oral diet, this study considered patients eligible for transition independent of their critical illness and nutrition status. In the DeSantis study, $80 \%$ of the average total amount of daily insulin given via continuous infusion was selected as the initial amount of subcutaneous insulin to administer. The current study used the insulin sensitivity factor to select a transition regimen eliminating potential mathematical and documentation errors. One value was required to determine the insulin transition regimen and resulted in a simpler and safer process for physicians.

Similar to The Northwestern Experience, the most common error observed in this study was the under dosing of insulin. Patients in this study correctly transitioned according to the transition protocol had $54 \%$ of blood sugars within goal range (target 70 $\mathrm{mg} / \mathrm{dL}>\mathrm{BBG}<180 \mathrm{mg} / \mathrm{dL}$ ) as compared to $58.3 \%$ of DeSantis' (target $80 \mathrm{mg} / \mathrm{dL}>$ BBG $<180 \mathrm{mg} / \mathrm{dL}$ ). As a result of this study, hopefully there will be an increase in compliance with the transition regimen selected.

Overall the study's glycemic control goals were consistent with current recommendations from the American Association of Clinical Endocrinologists and NICE-SUGAR Trial with a target glucose level less than $180 \mathrm{mg} / \mathrm{dL} .{ }^{8,14}$ Contrary to the current study, comparative studies used 40 or $50 \mathrm{mg} / \mathrm{dL}$ as the cutoff for hypoglycemia or severe hypoglycemia. ${ }^{1,7-8,12-13}$ Per the study hospital's definition (blood glucose $<70 \mathrm{mg} / \mathrm{dL}$ ) the "per protocol" group had two percent of blood sugars that were considered hypoglycemic; however, using comparative literature's standard there were no blood sugars less than $50 \mathrm{mg} / \mathrm{dL}$.

Despite being available to intensivists there was an overall lack of utilization of the protocol. This was secondary to concerns for increased development of hypoglycemia in patients previously not requiring insulin therapy. Additionally, patients were transitioned with lower amounts of basal insulin than the protocol recommended. However, study findings support the use of the recommended amount of basal insulin with no significant increased risk of hypoglycemia. Patients transitioned with lower amounts of basal insulin required increased correctional insulin for hyperglycemia. This likely contributed to the observed increased incidence of hypoglycemia in patients transitioned "off protocol."

Limitations of this study included a retrospective design and an overall lack of use of the transition order set resulting in a limited sample size. Further studies should be conducted with a larger sample. Additional studies should correlate blood sugar control with the history of diabetes or hemoglobin A1C at baseline.

\section{CONCLUSIONS}

Implementation of a formal transition order set significantly improved glycemic control in patients transitioned off of a continuous insulin infusion without adverse outcomes. Maintaining normoglycemia has demonstrated improvement in patient outcomes by decreasing infection rate and mortality. Additionally, by acutely controlling hyperglycemia long-term organ damage, a known consequence of poor glucose control, can hopefully be minimized. The findings of this study provide evidence of the effectiveness of an intensive insulin transition protocol in the ICU setting.

\section{CONFLICT OF INTEREST}

No conflicts of interest to disclose

No funding was received for research.

\section{References}

1. van den Berghe $G$, Wouters $P$, Weekers F, Verwaest $C$, Bruyninckx F, Schetz $M$, Vlasselaers D, Ferdinande $P$, Lauwers P, Bouillon R. Intensive Insulin Therapy in Critically III Patients. N Engl J Med. 2001;345(19):1359-1367.

2. van den Berghe G. How does blood glucose control with insulin save lives in the intensive care. J Clin Invest. 2004;114(9):1187-1195.

3. van den Berghe G, Wilmer A, Hermans G, Meersseman W, Wouters PJ, Milants I, van Wijngaerden E, Bobbaers H, Bouillon R. Intensive Insulin Therapy in the Medical ICU. N Engl J Med. 2006;354(5):449-461.

4. McCowen KC, Malhotra A, Bistrian BR. Stress-Induced Hyperglycemia. Crit Care Clin. 2001;17(1):107-124.

5. Pittas AG, Siegel, Lau J. Insulin Therapy for Critically III Hospitalized Patients. Arch Intern Med. 2004;164(18):20052011.

6. DeSantis AJ, Schmeltz LR, Schmidt K, O'Shea-Mahler E, Rhee C, Wells A, Brandt S, Peterson S, Molitch ME. Inpatient Management of Hyperglycemia: The Northwestern Experience. Endocr Pract. 2006;12(5):491-505.

7. Shogbon AO, Levy S. Intensive glucose control in the management of diabetes mellitus and inpatient hyperglycemia. Am J Health Syst Pharm. 2010;67(10):798-805.

8. NICE-SUGAR Study Investigators, Finfer S, Chittock DR, Su SY, Blair D, Foster D, Dhingra V, Bellomo R, Cook D, Dodek P, Henderson WR, Hébert PC, Heritier S, Heyland DK, McArthur C, McDonald E, Mitchell I, Myburgh JA, Norton R, Potter J, Robinson BG, Ronco JJ. Intensive versus Conventional Glucose Control in Critically III Patients. N Engl J Med. 2009;360(13):1283-1297. 
9. Furnary AP, Braithwaite SS. Effects of Outcome on In-Hospital Transition from Intravenous Insulin Infusion to Subcutaneous Therapy. Am J Cardiol. 2006;98(4):557-564.

10. Weant KA, Ladha A. Conversion from Continuous Insulin Infusions to Subcutaneous Insulin in Critically III Patients. Ann Pharmacother. 2009;43(4):629-634.

11. Rady MY, Johnson DJ, Patel BM, Larson JS, Helmers RA. Influence of Individual Characteristics on Outcome of Glycemic Control in Intensive Care Unit Patients With or Without Diabetes Mellitus. Mayo Clin Proc. 2005;80(12):15581567.

12. Schmeltz LR, DeSantis AJ, Schmidt K, O'Shea-Mahler E, Rhee C, Brandt S, Peterson S, Molitch ME. Conversion of Intravenous Insulin Infusions to Subcutaneously Administered Insulin Glargine in Patients with Hyperglycemia. Endocr Pract. 2006;12(6):641-650.

13. Olansky L, Sharon S, Lover C, Yared JP, Hoogwerf B. Cleveland Clinic Cardiovascular Intensive Care Unit Insulin Conversion Protocol. J Diabetes Sci Technol. 2009;3(3):478-486.

14. Moghissi ES, Korytkowski MT, DiNardo M, Einhorn D, Hellman R, Hirsch IB, Inzucchi SE, Ismail-Beigi F, Kirkman MS, Umpierrez GE; American Association of Clinical Endocrinologists; American Diabetes Association. American Association of Clinical Endocrinologist and American Diabetes Association consensus statement on inpatient glycemic control. Endocr Pract. 2009;15(4):353-369.

15. Kavanagh BP, McCowen KC. Glycemic Control in the ICU. N Engl J Med. 2010;363(26):2540-2546.

16. ACE/ADA Task Force on Inpatient Diabetes. American College of Endocrinology and American Diabetes Association consensus statement on inpatient diabetes and glycemic control: a call to action. Diabetes Care. 2006;29(8):1955-1962.

17. Edelman S, Dailey G, Flood T, Kuritizky L, Renda S. A practical approach for implementation of a basal-prandial insulin therapy regimen in patients with type 2 diabetes. Osteopath Med Prim Care. 2007;1:9.

18. Davidson PC, Steed RD, Bode BW. Glucommander: A computer-directed intravenous insulin system shown to be safe, simple, and effective in 120,618 h of operation. Diabetes Care. 2005;28(10):2418-2423.

19. American Diabetes Association. Standards of medical care in diabetes-2011. Diabetes Care. 2011;34(Suppl 1):S11S61.

20. Schmeltz LR, DeSantis AJ, Schmidt K, O'Shea-Mahler E, Rhee C, Brandt S, Peterson S, Molitch ME. Conversion of intravenous insulin infusions to subcutaneously administered insulin glargine in patients with hyperglycemia. Endocr Pract. 2006;12(6):641-650. 